\title{
LAYANAN BIMBINGAN KARIR DALAM UPAYA MENINGKATKAN KEMAMPUAN PERENCANAAN KARIR PADA SISWA KELAS XII SMK KESEHATAN INSAN MULIA YOGYAKARTA TAHUN AJARAN 2018/2019
}

\author{
Trihana Widiyanti ${ }^{(1)}$, Makin ${ }^{(2)}$ \\ Program Studi Bimbingan dan Konseling \\ Fakultas Keguruan dan Ilmu Pendidikan \\ Universitas PGRI Yogyakata \\ E-mail: hidayahsetyanti@gmail.com
}

\begin{abstract}
Abstrak
Penelitian bertujuan untuk mendeskripsikan pelaksanaan layanan bimbingan karir dalam upaya meningkatkan kemampuan siswa SMK Kesehatan Insan Mulia Yogyakarta dalam membuat perencanaan karir. Penelitian menggunakan pendekatan kualitatif. Analisis data dilakukan dengan: 1) Data Reduction (Reduksi Data), 2) Data Display (Penyajian Data), dan 3) Penarikan Kesimpulan. Selain itu dilakukan trianggulasi sebagai uji keabsahan data penelitian dengan menerapkan trianggulasi sumber dan teknik. Temuan hasil penelitian: 1) Layanan bimbingan karir SMK Kesehatan Insan Mulia Yogyakarta dilaksanakan dengan memberikan layanan bimbingan dan konseling kepada siswa, yaitu (a) layanan informasi diri sendiri; (b) layanan informasi tentang lingkungan hidup/pekerjaan; (c) layanan penempatan latihan kerja; dan (d) layanan orientasi. 2) Kemampuan perencanaan karir ditunjukkan melalui pemahaman tentang: (a) pilihan kelanjutan studi; (b) pilihan jenis karir/pekerjaan yang sesuai keaadaan diri sendiri; (c) sikap kerja di perusahaan; (d) cara membuat surat lamaran kerja; (e) kiat menghadapi wawancara kerja; dan (f) macam-macam profesi (jabatan). 3) Faktor yang mempengaruhi perencanaan karir siswa terbatas pada faktor kondisi lingkungan
\end{abstract}

Kata kunci: layanan bimbingan karir, perencanaan karir

\begin{abstract}
The research aims to describe the implementation of career guidance services in an effort to improve the ability of students of Mulia Mulia Health Vocational School in making career planning. Research uses a qualitative approach. Data analysis was carried out by: 1) Data Reduction (Data Reduction), 2) Data Display (Data Presentation), and 3) Conclusion Withdrawal. In addition, triangulation was conducted as a test of the validity of research data by applying source and technique triangulation. The findings of the research: 1) Career guidance services at Mulia Mulia Health Vocational School Yogyakarta are carried out by providing guidance and counseling services to students, namely (a) self-information services; (b) information services about the environment / work; (c) job training placement services; and (d) orientation services. 2) The ability of career planning is demonstrated through an understanding of: (a) the choice of continuation of study; (b) choice of type of career I occupation that is suitable for self; (c) work attitude in the company; (d) how to make a job application letter; (e) tips for dealing with job interviews; and (f) various types of professions (positions). 3) Factors affecting student career planning are limited to environmental conditions Keywords: career guidance services, career planning
\end{abstract}

\section{Info Artikel}

Diterima April 2019, disetujui Mei 2019, diterbitkan Juni 2019 


\section{PENDAHULUAN}

Bimbingan karir merupakan bagian integral sistem pendidikan. Urgensi penyelenggaraan bimbingan karir di sekolah terutama berkaitan dengan fasilitasi perkembangan aspek karir siswa sejalan dengan fungsi pendidikan untuk menghasilkan lulusan yang mempunyai kesiapan memasuki dunia kerja. Oleh karena itu keefektifan pelaksanaan bimbingan karir mengacu pada indikator pencapaian kompetensi kemandirian siswa dalam membuat perencanaan karir yang sesuai dengan kondisi obyektif dan subyektif dirinya menjadi salah satu faktor penentu akuntabelitas sekolah.

Pelaksanaan bimbingan karir di Sekolah Menengah Kejuruan (SMK) menghadapi problematika tersendiri terkait dengan pencapaian kemampuan siswa dalam membuat perencanaa karir masa depan. Sebab sejak awal masuk menjadi siswa SMK mereka sudah menentukan pilihan karirnya melalui pemilihan jurusan (bidang keahlian) tertentu, sedangkan mereka sesungguhnya belum cukup bekal pemahaman yang memadai untuk mendukung kesuksesan karir yang menjadi pilihannya. Dampak dari spekulasi pilihan karis tersebut, terjadi perubahan aspirasi pendidikan para siswa. Sebagian tetap dalam aspirasi memilih pendidikan di SMK berharap segera bisa bekerja dalam bidang keahlian yang menjadi pilihannya, sebagian berubah aspirasi untuk melanjutkan studi di perguruan tinggi dengan pilihan program studi yang relevan atau sama sekali tidak relevan dengan bidang keahlian yang ditekuni di SMK. Problematika tersebut tentu berimplikasi terhadap kinerja Guru bimbingan dan konseling yang harus menerapkan prinsip pemberian layanan bimbingan berdasarkan hasis asesmen kebutuhan siswa yang dilayani.

Problematika pelaksanaan bimbingan karir yang dipaparkan di atas juga terjadi di SMK Kesehatan Insan Mulia Yogyakarta. Hasil wawancara dengan Guru bimbingan dan konseling didapatkan fenomena terkait problematika tersebut, yakni: 1) layanan bimbingan karir hanya diberikan di kelas XII, untuk kelas XI dan X belum diberikan karena tidak adanya jam masuk kelas; 2) sebagian siswa kelas XII belum mampu membuat perencanaan karirnya (pekerjaan, profesi, jabatan) dengan matang; 3) sebagian siswa kelas XII masih kebinggungan dalam memilih antara melanjutkan ke perguruan tinggi atau langsung terjun ke dunia kerja; 4) sebagian siswa kelas XII hanya mengikuti teman atau pendapat orang tua dalam pemilihan jurusan/bidang keahlian; 5) sebagian siswa kelas XII yang melanjutkan studi ke perguruan tinggi mengambil 
jurusan yang berbeda atau tidak sesuai dengan jurusan/bidang keahlian yang ditekuni di SMK.

Berdasarkan paparan di atas maka perlu penelitian berfokus pada masalah bagaimana pelaksanaan bimbingan karir dalam upaya meningkatkan kemampuan siswa SMK Kesehatan Insan Mulia Yogyakarta dalam membuat perencanaan karir.

\section{KAJIAN TEORI}

\section{Bimbingan Karir}

Menurut Bimo Walgito (2010: 203) layanan bimbingan karir merupakan usaha untuk mengetahui dan memahami diri, memahami apa yang ada dalam diri sendiri dengan baik, mengetahui potensi yang ada dalam dirinya, serta mengatasi hambatan apa yang sekiranya ada. Syamsu Yusuf dan Juantika Nurihsan (2010:12) menjelaskan layanan bimbingan karir merupakan upaya bantuan terhadap individu agar dapat mengenal dan memahami dirinya, mengenal dunia kerjanya, mengembangkan masa depannya yang sesuai dengan bentuk kehidupannya yang diharapkan. Hal senada dikemukakan oleh Tohirin (2013:130) bahwa layanan bimbingan karir merupakan bantuan dalam mempersiapkan diri menghadapi dunia pekerjaan, pemilihan lapangan pekerjaan atau jabatan (profesi) tertentu serta membekali diri agar siap memangku jabatan tersebut dan dalam menyesuaikan diri dengan tuntutan-tuntutan dari lapangan pekerjaan yang telah dimasuki. Dengan demikian dapat disimplukan bahwa layanan bimbingan karir merupakan upaya bantuan terhadap individu agar memahami dan mengetahui potensi yang ada dalam dirinya, mengatasi hambatan-hambatan yang ada, mengembangkan masa depannya, serta mempersiapkan diri menghadapi dunia pekerjaan di masa depan.

\section{Perencanaan Karir}

Menurut Supriatna dan Budiman (Salis, 2015:22) perencanaan karir adalah aktivitas siswa yang mengarah pada keputusan karir masa depan. Mengutip pendapat Winkel dan Sri Hastuti, Salis juga mengemukakan perencanaan karir sebagai proses yang dilalui sebelum melakukan pemilihan karir. Proses ini mencakup tiga aspek utama yaitu pengetahuan dan pemahaman akan diri sendiri, pengetahuan dan pemahaman akan pekerjaan, serta penggunaan penalaran yang benar antara diri sendiri dan dunia kerja. 
Dengan demikian perencanaan karir merupakan proses pengambilan keputusan tentang pilihan karir berdasarkan pemahaman terhadap diri sendiri, pemahaman terhadap jenis pekerjaan, serta kesesuaian antara keduanya.

Pentingnya perencanaan karir bagi siswa SMK didasarkan atas beberapa alasan (Salis, 2015: 29) yaitu: 1) siswa SMK merupakan angkatan kerja yang potensial; 2) kenyataan menunjukan bahwa siswa SMK sedang berada dalam masa peralihan dari masa kanak-kanak kamasa dewasa, mereka belum dapat mandiri sehingga masih memerlukan bantuan dari orang lain untuk menuju kemandirian; 3) siswa SMK memerlukan perencanaan karir, baik untuk melanjutkan pendidikan yang lebih tinggi maupun pekerjaan.

\section{Faktor-faktor yang Mempengaruhi Perencanaan Karir}

Kemampuan siswa dalam mengambil keputusan karir untuk masa depan menjadi aspek inti dari perencanaan karir yang dalam prosesnya dipengaruhi oleh banyak faktor. Krumboltz (Ardiatna Aminnurrohim, dkk, 2014: 58) menyebutkan beberapa faktor yang mempengaruhi pengambilan keputusan karir meliputi: 1) faktor genetik, berupa wujud keadaan fisik dan kemampuan-kemampuan khusus seperti kecerdasan dan bakat; 2) kondisi lingkungan, berupa kesempatan kerja, kesempatan pendidikan dan pelatihan, peristiwa alam, perubahan dalam organisasi sosial, keluarga, system pendidikan, lingkungan tetangga dan masyarakat; 3) pengalaman belajar, sebagai faktor yang mempengaruhi tingkah laku dan keputusan seseorang, antara lain tingkah laku dalam pemilihan karir; 4) ketrampilan menghadapi tugas, termasuk di dalam ketrampilan yang berhubungan dengan pemenuhan standar kerja, nilai kinerja, kebiasaan kerja. Individu dapat menerapkan ketrampilan-keterampilan tersebut untuk menghadapi dan menangani tugas-tugas baru.

\section{METODE PENELITIAN}

Penelitian dilakukan di Sekolah Menengah Kejuruan (SMK) Kesehatan Insan Mulia Yogyakarta yang beralamat di Jl. Gambir Sawit No.4 Pandeyan, Umbulharjo, Kota Yogyakarta, Daerah Istimewa Yogyakarta. Urgensi penelitian di SMK Kesehatan Insan Mulia Yogyakarta didasarkan pada karakteristik siswa yang memang lebih 
dipersiapkan untuk memasuki dunia kerja, selain itu SMK Kesehatan Insan Mulia Yogyakarta memiliki jurusan yang berbeda dengan SMK pada umumnya.

Penelitian menggunakan pendekatan kualitatif (qualitative research). Dengan pendekatan tersebut penelitian bermaksud mengungkapkan dan menggambarkan secara apa adanya tentang pelaksanaan layanan bimbingan karir dalam upaya meningkatkan kemampuan siswa kelas XII di SMK Kesehatan Insan Mulia Yogyakarta dalam membuat perencanaan karir. Berkaitan dengan maksud tersebut maka dilakukan pengumpulan data tentang: 1) pelaksanaan bimbingan karir; 2) kemampuan perencanaan karir siswa; dan 3) faktor-faktor yang mempengaruhi perencanaan karir siswa. Data tersebut dikumpulkan melalui wawancara mendalam dan penggunaan kuesioner, dari sumber data yang menjadi subyek penelitian yaitu Guru bimbingan dan konseling dan empat siswa kelas XII SMK Kesehatan Insan Mulia Yogyakarta. Analisis data dilakukan secara interaktif dan berlangsung secara terus menerus sampai tuntas sesuai langkah-langkah analisis data penelitian kualitatif: 1) Data Reduction (Reduksi Data) yaitu merangkum dan mengkategorikan data hasil penelitian, memilih hal-hal yang pokok, memfokuskan pada hal-hal yang penting, dicari tema dan polanya; 2) Data Display (Penyajian Data), yaitu menyajikan data dalam bentuk urian singkat, bagan, hubungan antar kategori data; dan 3) Penarikan Kesimpulan. Selain itu dilakukan trianggulasi sebagai uji keabsahan data penelitian dengan menerapkan trianggulasi sumber dan teknik. Trianggulasi sumber dilakukan dengan cara membandingkan data hasil wawancara Guru bimbingan dan konseling dengan hasil wawancara siswa. Sedangkan triangulasi teknik dilakukan dengan cara membandingkan data hasil wawancara dengan data yang dikumpulkan melaui angket (kuisioner).

\section{HASIL PENELITIAN DAN PEMBAHASAN}

Pelaksanaan Layanan Bimbingan Karir

Layanan bimbingan karir di SMK Kesehatan Insan Mulia Yogayakarta dilaksanakan oleh Guru bimbingan dan konseling melalui sejumlah kegiatan aktual yang disajikan dalam bagan sebagai berikut: 


\section{Bagan 1.}

Layanan Informasi Diri Sendiri

\section{Layanan Informasi Diri Sendiri}

1.Informasi tentang pemahaman diri, agar siswa dapat memahami dan menerima diri sendiri

2. Informasi cara atau usaha menggali potensi,bakat dan minat agar siswa dapat mengembangkan potensi,bakat dan minat yang dimilikinya

3. Informasi cara mengambil keputusan karir secara tepat sesuai dengan potensi, bakat dan minat agar membantu siswa dalam mengambil keputusan karirnya berdasarkan potensi, bakat dan minat

Bagan 2.

Layanan Informasi Tentang Lingkungan Hidup

\section{Layanan Informasi Tentang Lingkungan Hidup}

1.Layanan yang diberikan adalah informasi tentang dunia kerja, informasi macam-macam profesi (jabatan) yang dibutuhakan dan informasi terkait dengan tempat siswa melakukan PKL.

2. Dan juga mengunakan media brosur untuk memberikan informasi perguruan tinggi. 


\section{Bagan 3.}

Layanan Informasi Penempatan

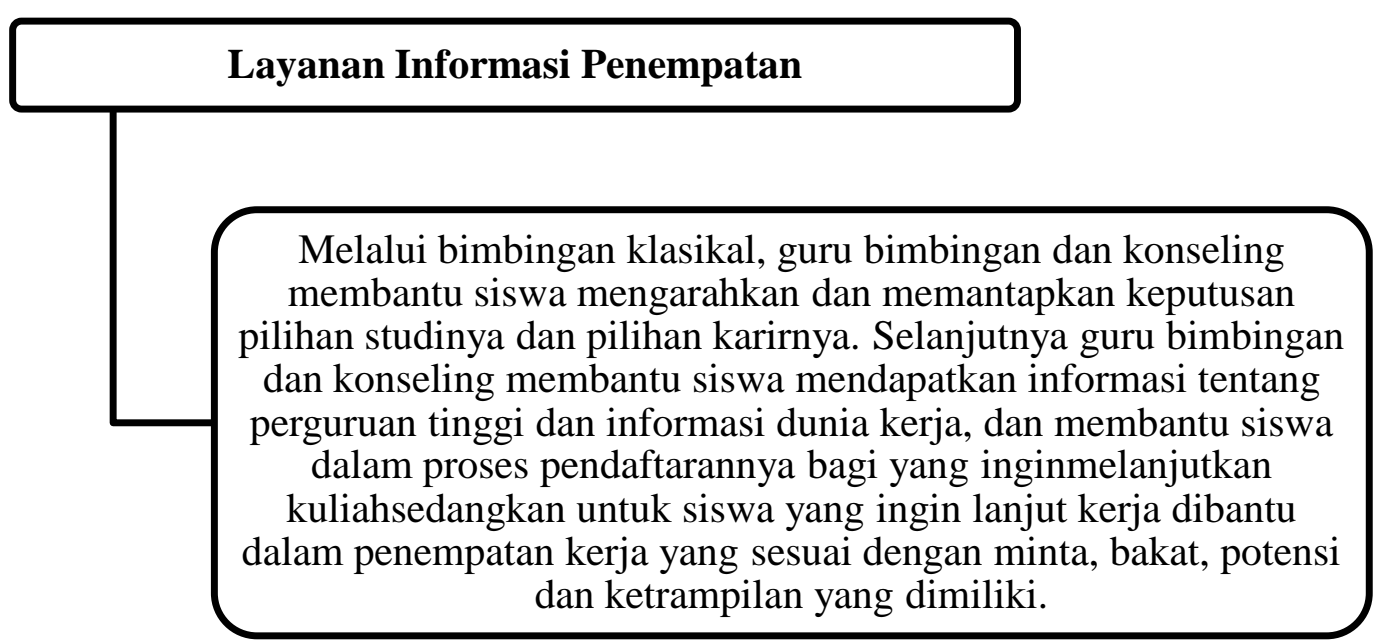

Bagan 4.

Layanan Orientasi

\section{Layanan Orientasi}

Layanan informasi terkait dengan tempat siswa melakukan PKL seperti rumah sakit, apotek, pabrik obat, dan homecare.

\section{Kemampuan Perencanaan Karir Siswa}

Kemampuan perencanaan karir siswa ditunjukkan melalui pemahaman terhadap diri sendiri dan pengetahuan tentang bunia kerja. Hasil penelitian disajikan dalam bagan sebagai berikut. 


\section{Bagan 5.}

Kemampuan Perencanaan Karir

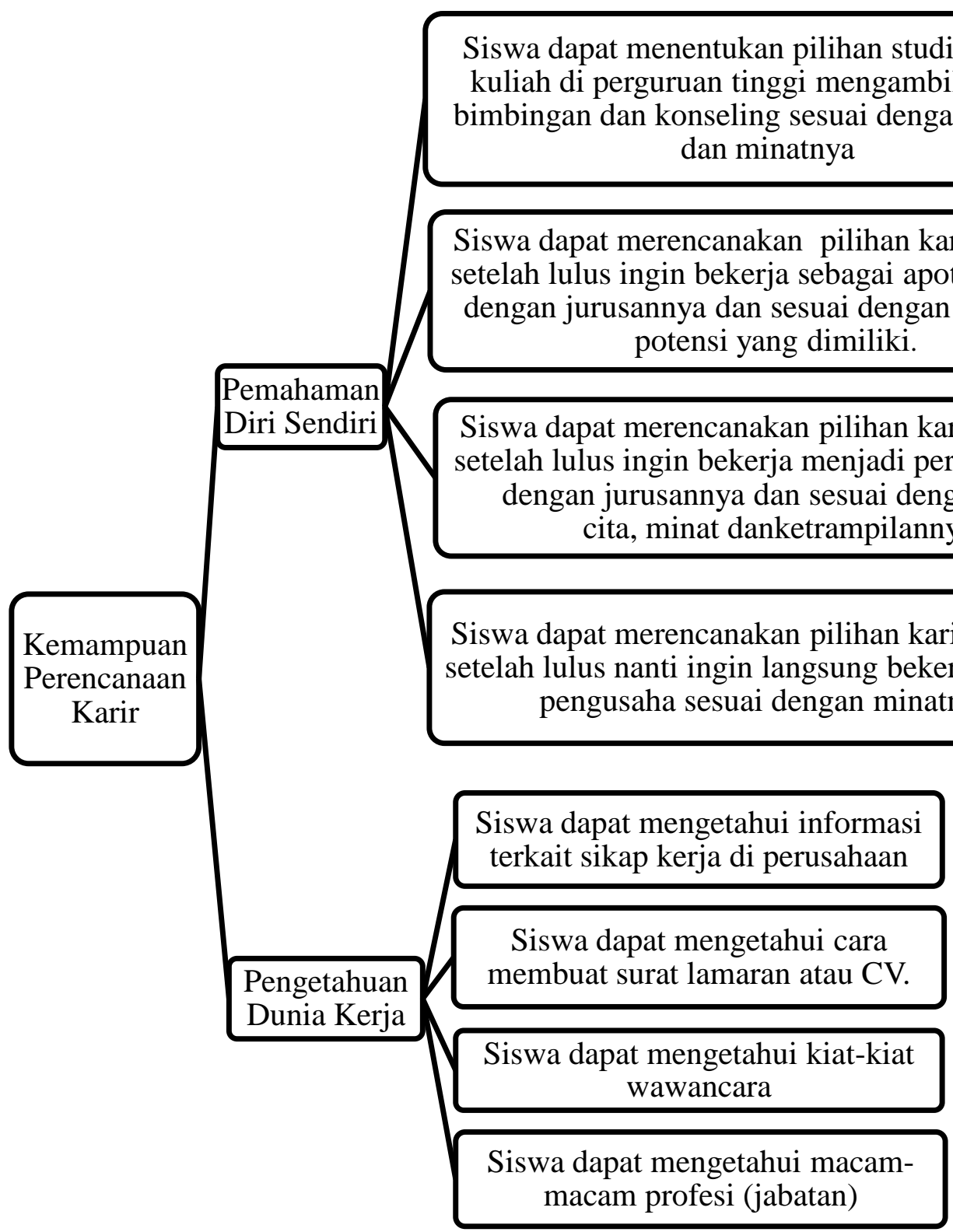

\section{Faktor-Faktor Yang Mempengaruhi Perencanaan Karir}

Hasil penelitian tentang faktor-faktor yang mempengaruhi perencanaan karir siswa disajikan dalam bagan sebagai berikut. 


\section{Bagan 6.}

Faktor Genetik

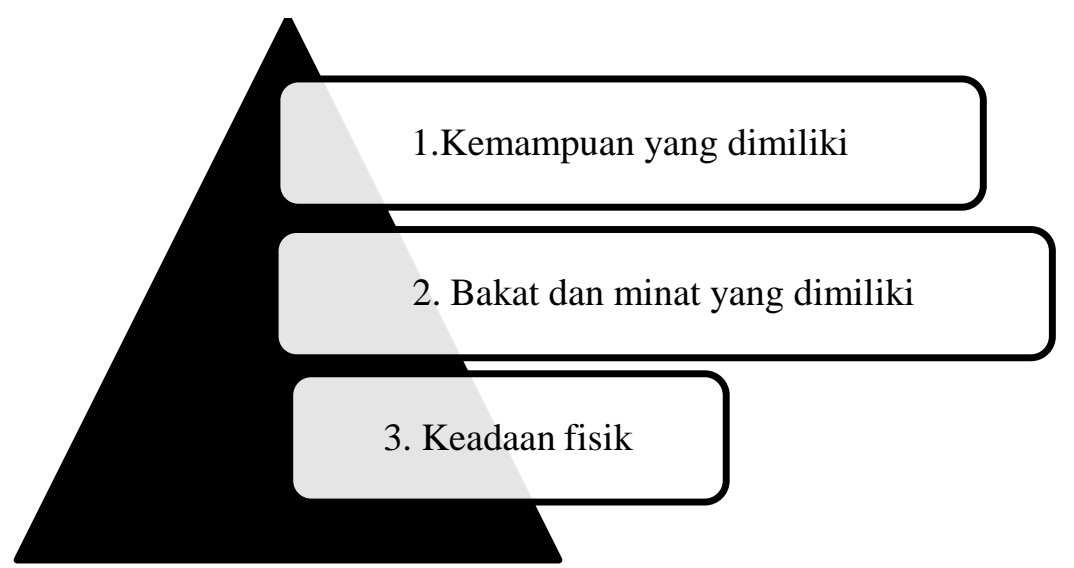

Keterangan : berdasarkan hasil data yang diperoleh, faktor yang menunjukan paling banyak diurutkan dari angka 1

$$
\text { Bagan } 7 .
$$

\section{Kondisi Lingkungan}

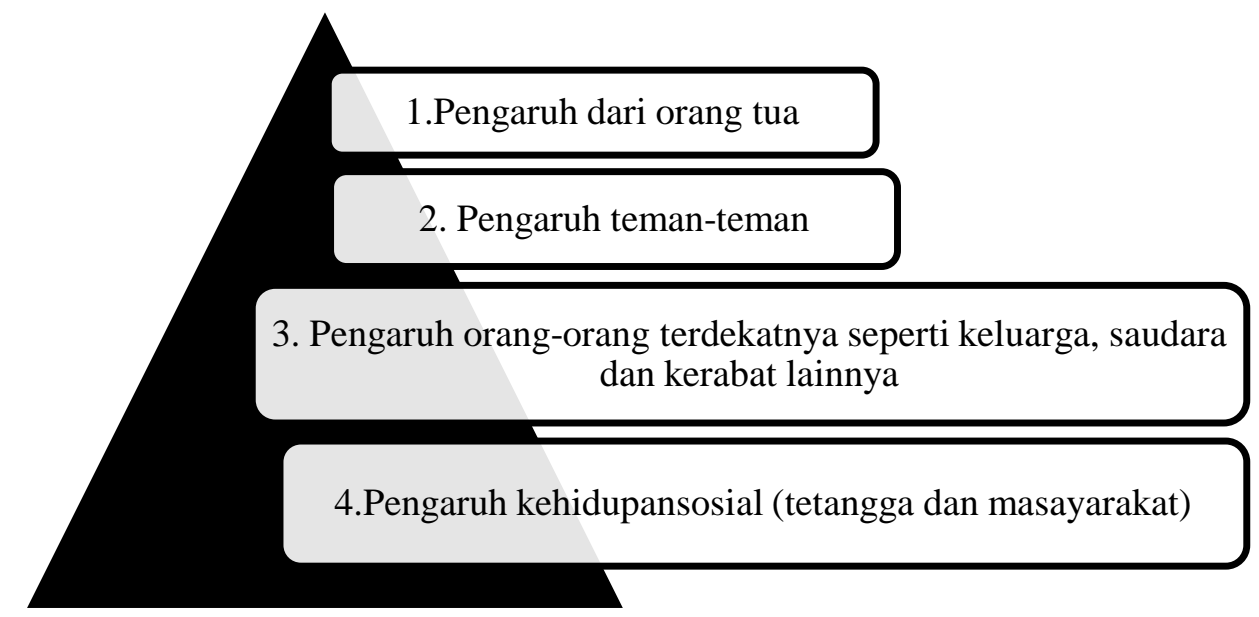

Keterangan : berdasarkan hasil data yang diperoleh, faktor yang menunjukan paling banyak diurutkan dari angka 1 
Bagan 8.

Pengalaman Belajar

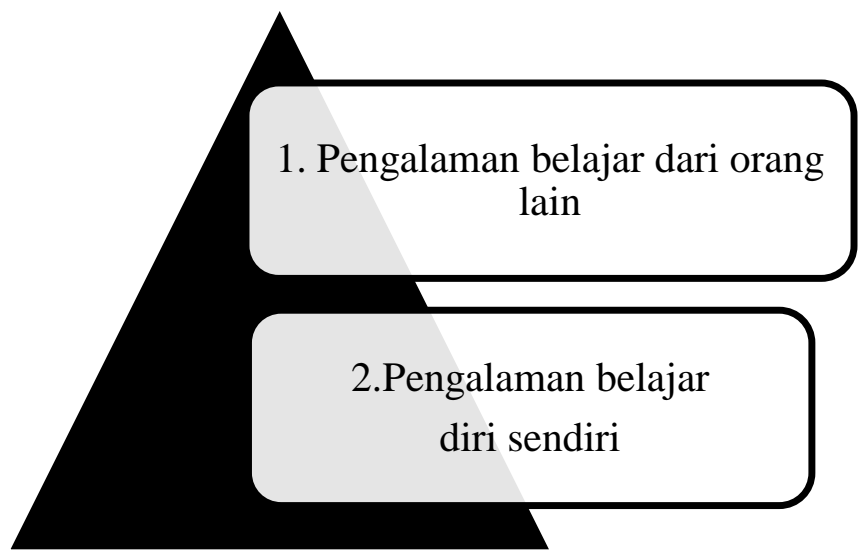

Keterangan : berdasarkan hasil data yang diperoleh, faktor yang menunjukan paling banyak diurutkan dari angka 1

Bagan 9.

Ketrampilan Menghadapi Tugas

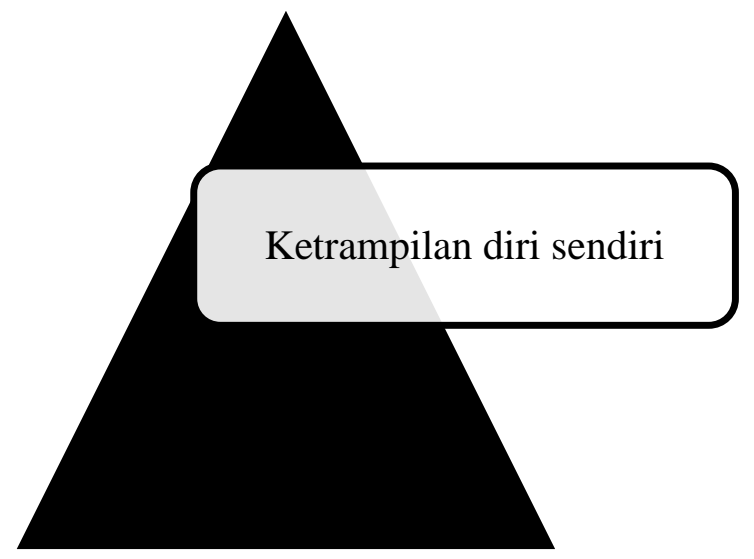

\section{KESIMPULAN DAN SARAN}

\section{Kesimpulan}

a. Pelaksanaan layanan bimbingan karir pada siswa kelas XII SMK Kesehatan Insan Mulia Yogyakarta meliputi a) layanan informasi tentang diri sendiri yang mencakup aspek pemahaman diri, cara atau usaha menggali potensi, bakat, minat dan cara mengambil keputusan karir secara tepat; b) layanan informasi tentang lingkungan hidup yaitu tentang dunia kerja, macam-macam profesi (jabatan), tempat siswa melakukan PKL, tentang perguruan tinggi; c) layanan informasi melalui bimbingan klasikal untuk mengarahkan siswa pada pilihan studi lanjutan dan pilihan karirnya. 
Selanjutnya diberikan informasi tentang perguruan tinggi dan dunia kerja. Bagi yang ingin melanjutkan kuliah dibantu dalam proses pendaftarannya sedangkan yang ingin kerja dibantu dalam penempatan kerja yang sesuai dengan minat, bakat, potensi dan ketrampilan yang dimiliki; d) layanan orientasi yang dilaksanakan bersamaan dengan pelaksanaan PKL di rumah sakit, apotek, pabrik obat, dan homecare.

b. Kemampuan perencanaan karir pada siswa kelas XII SMK Kesehatan Insan Mulia Yogyakarta ditunjukkan melalui beberapa hal: a) siswa dapat menentukan sendiri pilihan studinya yaitu melanjutkan studi ke perguruan tinggi sesuai dengan cita-cita dan minatnya; b) siswa dapat merencanakan sendiri pilihan karirnya yaitu setelah lulus ingin langsung terjun ke dunia kerja sesuai minat, potensi, cita-cita dan ketrampilan yang dimiliki; c) siswa mengetahui informasi terkait sikap kerja di perusahaan; d) siswa mengetahui cara membuat surat lamaran atau $\mathrm{CV}$; e) siswa mengetahui kiat-kiat wawancara; f) siswa mengetahui macam-macam profesi (jabatan).

c. Faktor-faktor yang mempengaruhi perencanaan karir pada siswa kelas XII SMK Kesehatan Insan Mulia Yogyakarta meliputi pengaruh dari orang tua, pengaruh teman-teman, pengaruh orang-orang terdekatnya seperti keluarga, saudara atau kerabat lainnya dan pengaruh kehidupan sosial (tetangga dan masayarakat).

\section{Saran}

Berdasarkan temuan hasil penelitian dapat diajukan saran sebagai berikut:

a. Bagi Guru Bimbingan dan Konseling hendaknya dapat memberikan layanan bimbingan karir secara maksimal untuk membantu siswa membuat perencanaan karir sesuai dengan bakat, minat dan karakteristik dirinya sehingga tidak mudah terpengaruh oleh keinginan orang tua atau sekedar mengikuti kecenderungan teman maupun lingkungan tetangga/masyarakat.

b. Bagi penelitian selanjutnya diharapkan dapat menindak lanjuti dengan mengembangkan penelitian yang lebih komprehensif dan mendalam berfokus efektifitas pelaksanaan bimbingan karir sesuai kebutuhan siswa SMK. 


\section{DAFTAR PUSTAKA}

Aminnurrohim, Ardiatna, dkk. 2014. "Survei Faktor-Faktor Penghambat Perencanaan Karir Siswa". Indonesian Journal of Guidance and Counseling: Theory and Application, 2014: 3(2).

Atmaja, Twi. 2014. "Upaya Meningkatkan Perencanaan Karir Siswa Melalui Bimbingan Karir dengan Penggunaan Media Modul". Psikopedagogia, (Online), 2014: Vol.3 No.2.

Bimo Walgito. 2010. Bimbingan Dan Konseling (Studi \&amp; Karir). Yogyakarta: Penerbit Andi.

Delan Setyawan. 2013. Self Disclosure Pada Remaja Tuna Daksa Dari Lahir. Skripsi tidak diterbitkan. Yogyakarta: Fakultas Ilmu Pendidikan Universitas Negeri Yogyakarta.

Eko Perianto. 2017. Manajemen Bimbingan Dan Konseling. Yogyakarta: Penerbit WR. Fitriana

Ermilasari. 2015. Hubungan Layanan Bimbingan Karir Dengan Minat Melanjutkan Studi Siswa Kelas VIII SMP Mataram Kasihan Bantul Tahun Ajaran 2015/2016. Skripsi tidak diterbitkan. Yogyakarta: Fakultas Keguruan dan Ilmu Pendidikan Universitas PGRI Yogyakarta.

Lexy J. Moeleong. 2005. Metode Penelitian Kualitatif. Bandung: Remaja Rosdakarya.

Massie, Renaldy, dkk. 2015. "Pengaruh Perencanaan Karir, Pelatihan Dan Pengembangan Karir Terhadap Kinerja Pegawai Pada Museum Negeri Privinsi Sulawesi Utara”. Jurnal Berkala Ilmiah Efisiensi, (Online), 2015: Vol 15 No. 05.

Nana Syaodih Sukmadinata. 2007. Bimbingan \&amp; Konseling Dalam Praktek. Bandung: Maestro.

Robert K. Yin. 2002. Studi Kasus. Jakarta: Raja Grafindo Persada.

Salis Nuroh Amaliyah, 2015. Hubungan antara konsep diri dengan Perencanaan Karir Siswa Kelas XI SMK N 1 Temon Tahun Ajaran 2015/2016. Bimbingan Dan Konseling. Skripsi tidak diterbitkan. Yogyakarta: Fakultas Keguruan dan Ilmu Pendidikan Universitas PGRI Yogyakarta.

Saifuddin Azwar. 2010. Metode Penelitian. Yogyakarta: Pustaka Pelajar Offset.

Sugiyono. 2007. Memahami Penelitian Kualitatif. Bandung: CV. Alfabeta. . 2011. Metode Penelitian Kuantitatif Kualitatif Dan R\&amp;D. Bandung: CV. Alfabeta.

Suharsimi Arikunto. 2009. Manajemen Penelitian. Jakarta: Rineka Cipta. 
. 2013. Prosedur Penelitian Suatu Pendekatam Praktrek. Jakarta: Rineka Cipta.

Yusuf, S dan Nurihsan, J. 2010. Landasan Bimbingan Dan Konseling. Bandung: Remaja Rosdakarya.

Tohirin. 2007. Bimbingan Dan Konseling Di Sekolah Dan Madrasah (Berbasis Integrasi). Jakarta: Raja Grafindo Persada.

Wardiati dan Jauhar, M. 2011. Implementasi Bimbingan \&amp; Konseling Di Sekolah. Jakarta: Prestasi Pustakarya.

W.S Winkel. Bimbingan Dan Konseling Di Institusi Pendidikan. 1991. Jakarta: PT. Grasindo. 